\title{
ASPECTOS DA ADOÇÃO HOMOPARENTAL EM FACE DA LEI E DA JURISPRUDÊNCIA
}

\author{
Renata Duval Martins ${ }^{1}$
}

\section{INTRODUÇÃO}

O presente trabalho tem por escopo analisar a adoção homoparental, especificamente a (in)existência de legislação clara sobre o tema, bem como a jurisprudência que permite a fruição deste direito, tendo em vista a falta de amparo legislativo. Destarte, frisar-se-á que foi o reconhecimento pelo Judiciário da união homoafetiva como entidade familiar que permitiu a estes casais o acesso a todos os direitos decorrentes da união estável e do casamento. Além disso, a omissão do legislador decorre de interesses políticos fundados na perspectiva hete- rossexual cristã a respeito do modelo correto de entidade familiar.

No primeiro capítulo, intitulado “A união homoafetiva”, será analisado o histórico da luta pela equiparação das uniões estáveis homoafetivas às uniões estáveis heterossexuais, percorrendo-se os posicionamentos doutrinários sobre o tema, as interpretações das normas da Constituição Federal e do Código Civil, a aplicação do princípio da dignidade humana, do princípio da igualdade e da analogia, bem como a brilhante atuação do Judiciário em suprir esta grave violação aos direitos humanos que o Legislativo cometeu ao excluir a união ho-

1 Mestranda em Direito do Trabalho pela Universidade Federal do Rio Grande do Sul, especialista em Direito e Processo do Trabalho pela Universidade Anhanguera, assistente em Administração na Universidade Federal do Rio Grande do Sul, advogada. 
moafetiva do conceito de entidade familiar.

No segundo capítulo, denominado "Adoção: evolução, fundamentos legais e requisitos”, será analisada a história do instituto da adoção desde que passou a integrar a legislação brasileira no Código Civil de 1916, até o seu novo tratamento mais humanizado na Constituição Federal de 1988, no Estatuto da Criança e do Adolescente e no Código Civil de 2002. Também será analisada a já ultrapassada dicotomia filiação legítima e filiação adotiva, bem como a atual filiação socioafetiva. Por fim, será analisado o requisito do estado civil do adotante, que por longo tempo foi empecilho à adoção homoparental.

Derradeiramente, o último capítulo do presente trabalho - Aspectos da adoção homoparental no Brasil versará sobre a omissão legislativa a respeito do tema, e como esta foi suprida pela jurisprudência amparada em forte doutrina. Ademais, ressaltar-se-á a importância da decisão do Supremo Tribunal Federal que, reconhecendo serem as uniões homoafetivas também uniões estáveis - não mais relegadas ao Direito Obrigacional e identificadas como sociedades de fato - permitiu aos casais homoafetivos constituir família por meio de adoção por casal ou adoção conjunta.

Portanto, no presente trabalho, sem a pretensão de exaurir o tema proposto, intentar-se-á refletir acerca da adoção homoparental hodiernamente, bem como sua correspondência com o proposto pela legislação brasileira. Ressaltando-se a necessidade de um Poder Legislativo que não se omita diante da violação dos direitos das minorias.

\section{A UNIÃO HOMOAFETIVA}

A sociedade tem experimentado profundas transformações nas relações afetivas, e estas mudanças comportamentais se refletem no Direito de Família. O debate acerca da união civil entre pessoas do mesmo sexo perdurou por longo tempo e abarcava tanto a natureza jurídica destas uniões quanto seus reflexos. Eram duas as correntes doutrinárias e jurisprudenciais sobre o tema: a conservadora e a avançada ou liberal.

A corrente conservadora defendia que: a união entre pessoas do mesmo sexo fosse tratada como sociedade de fato; não fossem reconhecidos às partes direito a alimentos, meação, direitos sucessórios, direito à adoção conjunta; fosse reconhecido direito a participação patrimonial sobre os bens adquiridos pelo esforço comum, com fulcro na Súmula 380 do Supremo Tribunal Federal; as questões relativas à união entre pessoas do mesmo sexo fossem apreciadas pela Vara Cível, pois eram questões resolvidas pelo Direito das Obrigações. En- 
quanto a corrente avançada ou liberal sustentava que: a união homoafetiva fosse reconhecida como entidade familiar; fossem aplicadas, por analogia, todas as regras relativas à união estável à união homoafetiva; as questões relativas à união entre pessoas do mesmo sexo fossem apreciadas pela Vara de Família (Tartuce, 2011, p. 212 e 214).

A corrente conservadora fundamentava a sua posição no texto constitucional, pois, neste, o legislador optou por incluir como requisito objetivo a dualidade de sexos para o reconhecimento da união estável como entidade familiar. No entanto, esse favoritismo legislativo jamais obstou a existência de uniões de pessoas do mesmo sexo com autêntico caráter matrimonial.

O critério da dualidade de sexos que consta no artigo 226, $\S 3^{\circ}$, da Constituição Federal, ${ }^{2}$ bem como no artigo 1.723 do Código Civil, ${ }^{3}$ trata-se de um elemento caracterizador da entidade familiar, fundamentado na moral do passado que excluía as uniões homoafetivas do Direito de Família - relegando a tutela de seu re- lacionamento ao campo obrigacional (sociedades de fato) -, justificando-se na suposta impossibilidade de ser experimentada a paternidade ou a maternidade em uniões homoafetivas.

[...] não se pode olvidar que, mesmo os casais homossexuais poderão, eventualmente, experimentar a paternidade, através de reprodução assistida e da adoção, conforme vem reconhecendo a jurisprudência mais recente. A outro giro, também não se pode submeter a caracterização de família à decorrência de prole, uma vez que o planejamento familiar é opção do casal, não se descaracterizando uma família somente pela inexistência de filhos. ${ }^{4}$

$\mathrm{O}$ argumento da impossibilidade de filiação por casal de homossexuais não se sustenta, pelas seguintes razões: a) a família sem filhos é família tutelada constitucionalmente; b) a procriação não é finalidade indeclinável da família constitucionalizada; c) a adoção é permitida a qualquer pessoa, independentemente do estado civil (art. 42 do ECA e art. 1.618 do Código Civil), e não impede que a criança se integre à família, ainda que o parentesco civil seja apenas com um dos parceiros. ${ }^{6}$

2 Para efeito da proteção do Estado é reconhecida a união estável entre o homem e a mulher como entidade familiar, devendo a lei facilitar sua conversão em casamento.

3 É reconhecida como entidade familiar a união estável entre o homem e a mulher, configurada na convivência pública, contínua e duradoura e estabelecida com o objetivo de constituição de família.

4 FARIAS, Cristiano Chaves de; ROSENVALD, Nelson. Direito das Famílias. p. 451. 5 LÔBO, Paulo. Direito Civil: Famílias. p. 91. 
Além da moral do passado calcada na ideologia cristã, outro fator relevante para a existência na lei de uma regra que claramente marginaliza as uniões homoafetivas se encontra no fato de o legislador "com medo da reprovação de seu eleitorado" preferir "não aprovar leis que concedam direitos às minorias, alvo da discri-

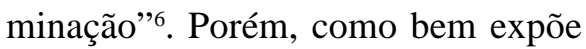
Maria Berenice Dias, "a ausência de lei não significa inexistência de direito"7 e não se deve confundir "a carência legislativa com inexistência de direito". 8

Apesar da adoção pelo legislador, bem como parte da doutrina, do critério da dualidade de sexos, a jurisprudência, em sentido oposto, passou a garantir aos casais homoafetivos direitos iguais aos dos casais heterossexuais com base no princípio da dignidade humana e no da igualdade e na analogia. Com base no princípio da dignidade humana, verifica-se que o respeito à orientação sexual é imprescindível para a afirmação da dignidade humana, cabendo ao Estado - além de se abster de invasões ilegítimas na esfera pessoal dos indivíduos - pro- mover positivamente as liberdades destes. Com relação ao princípio da igualdade, observa-se que este não se restringe apenas ao nivelamento dos cidadãos diante da norma legal, impondo-se também que "a própria lei não pode ser editada em desconformidade com a isonomia". ${ }^{9}$ Por fim, a analogia atua sobre a questão ressaltando a semelhança dos casais heterossexuais e dos casais homossexuais, logo, sendo fatos semelhantes e sendo ambas uniões duradouras fundadas em afeto e cuidado mútuo, concluise que devem ser reguladas de modo idêntico.

Outrossim, junta-se às justificativas acima arroladas para a caracterização das uniões homossexuais como entidade familiar, o fato de os princípios da dignidade humana e o da igualdade - assim como a base do argumento contrário, ou seja, o critério da dualidade de sexos (artigo 226, § $3^{\circ}, \mathrm{CF}$ ) - terem previsão constitucional, dispostos respectivamente no artigo $1^{\circ}$, III e no artigo $5^{\circ}$, caput da Constituição Federal. Além disso, o artigo 226, caput, da Constituição Federal "é cláusula geral de inclusão,

6 DIAS, Maria Berenice. Manual de Direito das Famílias. p. 197.

7 Idem.

8 Idem, p. 202.

9 GIORGIS, José Carlos Teixeira. Direito de Família Contemporâneo. p. 308. 
não sendo admissível excluir qualquer entidade que preencha os requisitos de afetividade, estabilidade e ostensibilidade" ${ }^{10}$ do conceito de entidade familiar, desde que tenha a finalidade de constituição de família. Logo, para que a norma do artigo 226, caput, da Constituição Federal seja excepcionada é necessário a edição de outra norma que exclua explicitamente da tutela as uniões homoafetivas. ${ }^{11}$

Respeito, mútua assistência, afeto, solidariedade e lealdade, entre outros, devem estar presentes em todos os tipos de uniões, inclusive na homoafetiva, sendo inaceitável a discriminação contida no $\S 3^{\circ}$ do art. 226 da CRFB/88, em confronto com o princípio da igualdade, ao reconhecer como entidade familiar somente a união estável entre o "homem e a mulher”. A proteção estatal é devida a qualquer tipo de família que tenha por base o afeto, independentemente do seu formato e da orientação sexual dos seus membros. ${ }^{12}$

A evolução histórica do conceito de entidade familiar a fim de incluir a união homoafetiva iniciou pela justiça gaúcha em 1999, quando foi definida a competência dos juizados especializados da família para apreciar as ações relativas às uniões homoafetivas e, em 2001, a mesma justiça reconheceu pela primeira vez "a união de pessoas do mesmo sexo como entidade familiar". ${ }^{13}$

Dez anos após esta importante decisão, no ano de 2011, o Supremo Tribunal Federal no julgamento conjunto da Ação Direta de Inconstitucionalidade n. 4.277 (tendo por objeto o artigo 1.723 do Código Civil) e da Arguição de Descumprimento de Preceito Fundamental n. 132, também reconheceu o casamento entre pessoas do mesmo sexo e a união estável homoafetiva como entidade familiar. E, em 2013, o Conselho Nacional de Justiça aprovou a Resolução n. 175, determinando a todos os cartórios do país a celebrar casamentos entre pessoas do mesmo sexo.

1. ARGUIÇÃO DE DESCUMPRIMENTO DE PRECEITO FUNDAMENTAL (ADPF). PERDA PARCIAL DE OBJETO. RECEBIMENTO, NA PARTE REMANES-

10 PENA JR., Moacir César. Direito das pessoas e das famílias doutrina e jurisprudência. p. 170.

11 LÔBO, Paulo. Direito Civil: Famílias. p. 90.

12 PENA JR., Moacir César. Direito das pessoas e das famílias doutrina e jurisprudência. p. 170-171.

13 DIAS, Maria Berenice. Manual de Direito das Famílias. p. 205. 
CENTE, COMO AÇÃO DIRETA DE INCONSTITUCIONALIDADE. UNIÃO HOMOAFETIVA E SEU RECONHECIMENTO COMO INSTITUTO JURÍDICO. CONVERGÊNCIA DE OBJETOS ENTRE AÇÕES DE NATUREZA ABSTRATA. JULGAMENTO CONJUNTO. Encampação dos fundamentos da ADPF n. 132-RJ pela ADI n. 4.277DF, com a finalidade de conferir "interpretação conforme a Constituição" ao art. 1.723 do Código Civil. Atendimento das condições da ação. 2. PROIBIÇÃO DE DISCRIMINAÇÃO DAS PESSOAS EM RAZÃO DO SEXO, SEJA NO PLANO DA DICOTOMIA HOMEM/MULHER (GÊNERO), SEJA NO PLANO DA ORIENTAÇÃO SEXUAL DE CADA QUAL DELES. A PROIBIÇÃO DO PRECONCEITO COMO CAPÍTULO DO CONSTITUCIONALISMO FRATERNAL. HOMENAGEM AO PLURALISMO COMO VALOR SÓCIO-POLÍTICO-CULTURAL. LIBERDADE PARA DISPOR DA PRÓPRIA SEXUALIDADE, INSERIDA NA CATEGORIA DOS DIREITOS FUNDAMENTAIS DO INDIVÍDUO, EXPRESSÃO QUE É DA AUTONOMIA DE VONTADE. DIREITO À INTIMIDADE E À VIDA PRIVADA. CLÁUSULA PÉTREA. O sexo das pessoas, salvo disposição constitucional expressa ou implícita em sentido contrário, não se presta como fator de desigualação jurídica. Proibição de preconceito, à luz do inciso IV do art. $3^{\circ}$ da Constituição Federal, por colidir frontalmente com o objetivo constitucional de "promover o bem de todos". Silêncio normativo da Carta Magna a respeito do concreto uso do sexo dos indivíduos como saque da kelseniana "norma geral negativa", segundo a qual "o que não estiver juridicamente proibido, ou obrigado, está juridicamente permitido". Reconhecimento do direito à preferência sexual como direta emanação do princípio da "dignidade da pessoa humana": direito à autoestima no mais elevado ponto da consciência do indivíduo. Direito à busca da felicidade. Salto normativo da proibição do preconceito para a proclamação do direito à liberdade sexual. $\mathrm{O}$ concreto uso da sexualidade faz parte da autonomia da vontade das pessoas naturais. Empírico uso da sexualidade nos planos da intimidade e da privacidade constitucionalmente tuteladas. Autonomia da vontade. Cláusula pétrea. 3. TRATAMENTO CONSTITUCIONAL DA INSTITUIÇÃO DA FAMÍLIA. RECONHECIMENTO DE QUE A CONSTITUIÇÃO FEDERAL NÃO EMPRESTA AO SUBSTANTIVO "FAMÍLIA" NENHUM SIGNIFICADO ORTODOXO OU DA PRÓPRIA TÉCNICA JURÍDICA. A FAMÍLIA COMO CATEGORIA SOCIOCULTURAL E PRINCÍPIO ESPIRITUAL. DIREITO SUBJETIVO DE CONSTITUIR FAMÍLIA. INTERPRETAÇÃO NÃO REDUCIONISTA. O caput do art. 226 confere à família, base da sociedade, especial proteção do Estado. Ênfase constitucional à instituição da família. Família em seu coloquial ou proverbial significado de núcleo doméstico, pouco importando se formal ou informalmente constituída, ou se integrada por casais heteroafetivos ou por pares homoafetivos. A Constituição de 1988, ao utilizar- 
-se da expressão “família”, não limita sua formação a casais heteroafetivos nem à formalidade cartorária, celebração civil ou liturgia religiosa. Família como instituição privada que, voluntariamente constituída entre pessoas adultas, mantém com o Estado e a sociedade civil uma necessária relação tricotômica. Núcleo familiar que é o principal locus institucional de concreção dos direitos fundamentais que a própria Constituição designa por "intimidade e vida privada" (inciso $\mathrm{X}$ do art. $5^{\circ}$ ). Isonomia entre casais heteroafetivos e pares homoafetivos que somente ganha plenitude de sentido se desembocar no igual direito subjetivo à formação de uma autonomizada família. Família como figura central ou continente, de que tudo o mais é conteúdo. Imperiosidade da interpretação não reducionista do conceito de família como instituição que também se forma por vias distintas do casamento civil. Avanço da Constituição Federal de 1988 no plano dos costumes. Caminhada na direção do pluralismo como categoria sócio-político-cultural. Competência do Supremo Tribunal Federal para manter, interpretativamente, o Texto Magno na posse do seu fundamental atributo da coerência, o que passa pela eliminação de preconceito quanto à orientação sexual das pessoas. 4. UNIÃO ESTÁVEL. NORMAÇÃO CONSTITUCIONAL REFERIDA A HOMEM E MULHER, MAS APENAS PARA ESPECIAL PROTEÇÃO DESTA ÚLTIMA. FOCADO PROPÓSITO CONSTITUCIONAL DE ESTABELECER RELAÇÕES JURÍDICAS HORIZONTAIS OU SEM HIERARQUIA ENTRE AS
DUAS TIPOLOGIAS DO GÊNERO HUMANO. IDENTIDADE CONSTITUCIONAL DOS CONCEITOS DE “ENTIDADE FAMILIAR" E "FAMÍLIA". A referência constitucional à dualidade básica homem/ mulher, no $\S 3^{\circ}$ do seu art. 226, deve-se ao centrado intuito de não se perder a menor oportunidade para favorecer relações jurídicas horizontais ou sem hierarquia no âmbito das sociedades domésticas. Reforço normativo a um mais eficiente combate à renitência patriarcal dos costumes brasileiros. Impossibilidade de uso da letra da Constituição para ressuscitar o art. 175 da Carta de 1967/1969. Não há como fazer rolar a cabeça do art. 226 no patíbulo do seu parágrafo terceiro. Dispositivo que, ao utilizar da terminologia "entidade familiar", não pretendeu diferenciá-la da "família”. Inexistência de hierarquia ou diferença de qualidade jurídica entre as duas formas de constituição de um novo e autonomizado núcleo doméstico. Emprego do fraseado "entidade familiar" como sinônimo perfeito de família. A Constituição não interdita a formação de família por pessoas do mesmo sexo. Consagração do juízo de que não se proíbe nada a ninguém senão em face de um direito ou de proteção de um legítimo interesse de outrem, ou de toda a sociedade, o que não se dá na hipótese sub judice. Inexistência do direito dos indivíduos heteroafetivos à sua não equiparação jurídica com os indivíduos homoafetivos. Aplicabilidade do $\$ 2^{\circ}$ do art. $5^{\circ}$ da Constituição Federal, a evidenciar que outros direitos e garantias, não expressamente listados na Constituição, emergem "do regime e dos prin- 
cípios por ela adotados”, verbis: “Os direitos e garantias expressos nesta Constituição não excluem outros decorrentes do regime e dos princípios por ela adotados, ou dos tratados internacionais em que a República Federativa do Brasil seja parte". 5. DIVERGÊNCIAS LATERAIS QUANTO À FUNDAMENTAÇÃO DO ACÓRDÃO. Anotação de que os Ministros Ricardo Lewandowski, Gilmar Mendes e Cezar Peluso convergiram no particular entendimento da impossibilidade de ortodoxo enquadramento da união homoafetiva nas espécies de família constitucionalmente estabelecidas. Sem embargo, reconheceram a união entre parceiros do mesmo sexo como uma nova forma de entidade familiar. Matéria aberta à conformação legislativa, sem prejuízo do reconhecimento da imediata autoaplicabilidade da Constituição. 6. INTERPRETAÇÃO DO ART. 1.723 DO CÓDIGO CIVIL EM CONFORMIDADE COM A CONSTITUIÇÃO FEDERAL (TÉCNICA DA “INTERPRETAÇÃO CONFORME”). RECONHECIMENTO DA UNIÃO HOMOAFETIVA COMO FAMÍLIA. PROCEDÊNCIA DAS AÇÕES. Ante a possibilidade de interpretação em sentido preconceituoso ou discriminatório do art. 1.723 do Código Civil, não resolúvel à luz dele próprio, faz-se necessária a utilização da técnica de "interpretação conforme à Constituição”. Isso para excluir do dispositivo em causa qualquer significado que impeça o reconhecimento da união contínua, pública e duradoura entre pessoas do mesmo sexo como família. Reconhecimento que é de ser feito segundo as mesmas regras e com as mesmas consequências da união estável heteroafetiva. (ADI 4277, Relator: Min. AYRES BRITTO, Tribunal Pleno, julgado em 05/05/2011, DJe-198 DIVULG. EM: 13.10.2011. PUBLIC. EM: 14.10.2011. EMENT. VOL-0260703 PP-00341 RTJ VOL-00219- PP00212)

Ressalta-se que, antes mesmo desta decisão do Supremo Tribunal Federal, já se argumentava que não existia na legislação pátria a imposição de que o casamento poderia ocorrer apenas entre homem e mulher, esta imposição existia apenas com relação à união estável. Outrossim, após o advento da Lei Maria da Penha, em 2006, parte da doutrina também passou a defender que o conceito de família havia sido alargado, incluindo as uniões homoafetivas como entidade familiar.

Nem a Constituição nem a lei, ao tratarem do casamento, fazem qualquer referência ao sexo dos nubentes. Portanto, não há qualquer impedimento, quer constitucional, quer legal, para o casamento entre pessoas do mesmo sexo. Também, entre os impedimentos para o casamento, não se encontra a diversidade de sexo do par. $\mathrm{O}$ que obstaculiza a realização do casamento é somente o preconceito. Aliás, a construção doutrinária sobre casamento inexistente tem como único ponto de sustentação a alegada impossibilidade do casamento homossexual. 
Só o fato de a lei estabelecer (CC 1.565) que, pelo casamento, homem e mulher assumem mutuamente a condição de consortes, companheiros e responsáveis pelos encargos da família não significa que esteja limitando o casamento a heterossexuais. Simplesmente o que está afirmando é que tanto o homem como a mulher assumem tal condição, e não que necessariamente tenham de estar casados com pessoas do sexo oposto. Tanto é assim que vem aumentando o número de países que admitem o casamento entre pessoas independentemente do sexo do par.

Com o advento da Lei Maria da Penha (L 11.340/06), alargou-se o conceito de família para albergar as uniões homoafetivas. Apesar da referência do art. 1.514 a "homem e mulher", como afirma Roberto Lorea, derruba-se, enfim, a última barreira - meramente formal - para a democratização do acesso ao casamento no Brasil: a nova definição legal da família brasileira se harmoniza com o conceito de casamento "entre cônjuges" do art. 1.511 do Código Civil, não apenas deixando de fazer qualquer alusão à oposição de sexos, mas explicitando que a heterossexualidade não é condição para o casamento. [...].14

O conceito legal de família trazido pela Lei Maria da Penha insere no sistema jurídico também as uniões homoafetivas, quer as formadas por duas mulheres ou constituídas entre dois homens - todas configuram entidade familiar. Ainda que a lei tenha por finalidade proteger a mulher, acabou por cunhar um novo conceito de família, independentemente do sexo dos parceiros. Diz o seu art. 2. ${ }^{\circ}$ : "Toda mulher, independentemente de classe, raça, etnia, orientação sexual [...] goza dos direitos fundamentais inerentes à pessoa humana”. O parágrafo único do art. 5. ${ }^{\circ}$ reitera que independem de orientação sexual todas as situações que configuram violência doméstica e familiar. $\mathrm{O}$ preceito tem enorme repercussão. Como é assegurada proteção legal a fatos que ocorrem no ambiente doméstico, isso quer dizer que as uniões de pessoas do mesmo sexo são entidades familiares. [...] Assim, se família é a união entre duas mulheres, igualmente é família a união entre dois homens. Ainda que eles não se encontrem ao abrigo da Lei Maria da Penha, para todos os outros fins impõe-se este reconhecimento. ${ }^{15}$

Assim, verifica-se a ocorrência de uma mudança paradigmática da entidade familiar no Brasil. Pautando-se na lógica do afeto, agora se inclui a família homoafetiva, também chamada de família isossexual (de pessoas do mesmo sexo), no rol de famílias abrangidas pelo conceito de entidade

14 DIAS, Maria Berenice. Manual de Direito das Famílias. p. 154-155.

15 Idem, p. 208-209. 
familiar. ${ }^{16}$ Logo, sendo tanto a união heterossexual quanto a união homoafetiva "vínculos que têm igual propósito, qual seja, a concretização do direito fundamental à felicidade por meio do afeto", ${ }^{17}$ não há razão para que seja negado aos casais homoafetivos a fruição de quaisquer direitos permitidos aos casais heterossexuais.

\section{ADOÇÃO: EVOLUÇÃO, FUNDAMENTOS LEGAIS E REQUISITOS.}

Incluída no Código Civil de 1916, a adoção naquele diploma consistia em uma adoção simples, levada a efeito por escritura pública; o adotado recebia o nome de família do adotante e estabelecia relações de parentesco apenas com este e não com o restante do agrupamento familiar. Além disso, conforme o artigo 377 daquela codifi- cação, se o adotante concebesse um filho biológico, a adoção se tornava ineficaz, dissolvendo-se a relação parental e retornando o adotado à sua família de origem..$^{18}$

Apenas com a Lei 3.133/57 - esta deu nova redação ao artigo supracitado - passou a ser permitida a adoção por casais que já tivessem prole, não se desconstituindo o vínculo entre adotante e adotado em razão da superveniência de filhos legítimos. Porém, ainda neste contexto, havendo prole legítima não era possível ao filho adotado herdar do adotante, ou seja, a adoção não gerava efeitos sucessórios. ${ }^{19}$

Um marco no Direito Brasileiro em matéria de adoção, a Lei 4.655/65 (Código dos Menores) criou outra modalidade de adoção, a legitimação adotiva, esta era feita mediante "decisão judicial, era irrevogável e fazia cessar o vínculo de parentesco com a

16 SIMÃO, José Fernando. Questões Polêmicas: qual o Conceito Jurídico de Família? In: LAGRASTA NETO, Caetano; TARTUCE, Flávio; SIMÃO, José Fernando. Direito de Família. p. 172.

17 DIAS, Maria Berenice; LARRATÉA, Roberta Vieira. A constitucionalização das uniões homoafetivas. In: CHINELLATO, Silmara Juny de Abreu; FUJITA, Jorge Shiguemitsu; SIMÃO, José Fernando; ZUCCHI, Maria Cristina. Direito de Família no Novo Milênio. p. 377.

18 MONACO, Gustavo Ferraz de Campos. Novo regramento da adoção no direito brasileiro: codificar o mesmo ou um exemplo de codificação a droit constant? In: CHINELLATO, Silmara Juny de Abreu; FUJITA, Jorge Shiguemitsu; SIMÃO, José Fernando; ZUCCHI, Maria Cristina. Direito de Família no Novo Milênio. p. 555.

19 Idem, p. 555-556. 
família natural”. ${ }^{20}$ Outrossim, “a legitimação adotiva se fundamentava no princípio da conveniência do menor e de seu bem-estar, e, assim, atendia mais aos interesses deste do que aos interesses dos adotantes”. ${ }^{21}$ Em 1979, um segundo Código dos Menores, a Lei n. 6.697, distinguiu a adoção em duas espécies: a adoção simples; e a adoção plena.

A adoção simples foi considerada aquela destinada aos menores em situação irregular, regendo-se pelo modelo do Código Civil, nos termos do art. 27 da Lei n. 6.697/79, com algumas alterações, como as seguintes: não se constituía por escritura pública, mas sim por autorização judicial; instituiu-se o estágio de convivência com o menor; deferida a adoção, expedia-se mandado para averbação no registro público com o patronímico do interessado na adoção. A adoção plena se assemelhava, por sua vez, à legitimação adotiva instituída em 1965 e, portanto, atribuía a condição de filho ao adotado pata todos os efeitos, inclusive sucessórios, em caráter irrevogável, desligando-o dos vínculos parentais com a família de origem. A adoção plena somente poderia ser concedida em relação ao menor em situação irregular com idade infe- rior a sete anos - ou com idade até 18 anos, desde que o menor estivesse sob a guarda dos adotantes a contar do período anterior aos sete anos -, por solicitação de pessoas casadas há pelo menos cinco anos - tal prazo era relegado na hipótese de esterilidade de um dos cônjuges e desde que comprovada a estabilidade do casal. ${ }^{22}$

Com a Constituição Federal de 1988, a estrutura jurídica da adoção foi expressivamente alterada. E, em seus artigos 226 a 230, consagrou-se a proteção isonômica dos filhos. Deixando o filho adotivo de ser um filho de segunda categoria, assim, "a relação jurídica filiatória determinada pela adoção tem as mesmas qualificações e direitos reconhecidos aos filhos decorrentes do elo biológico”. ${ }^{23}$

No Brasil, após a Constituição de 1988, não há mais filho adotivo, mas adoção, entendida como meio para filiação, que é única. A partir do momento em que a adoção se conclui, com a sentença judicial e o registro de nascimento, o adotado se converte integralmente em filho. Em preceito arrojado e avançado, que inaugurou verdadeira revolução na matéria, a Constituição (art. 227, § $6^{\circ}$ ) estabele-

20 DIAS, Maria Berenice. Manual de Direito das Famílias. p. 482.

21 GAMA, Guilherme Calmon Nogueira da. Direito Civil: Família. p. 421.

22 Idem, p. 421-422.

23 FARIAS, Cristiano Chaves de; ROSENVALD, Nelson. Direito das Famílias. p. 912. 
ce que "os filhos, havidos ou não da relação do casamento, ou por adoção, terão os mesmos direitos e qualificações, proibidas quaisquer designações discriminatórias relativas à filiação". Nos quatrocentos e oitenta e oito anos anteriores da história da sociedade e do direito brasileiros, perdurou o princípio da desigualdade e a clara distinção entre filho legítimo e filho adotivo, que não se integrava totalmente à família adotante. ${ }^{24}$

A Constituição Federal de 1988 ao igualar filhos biológicos e adotados fez uma opção pela família socioafetiva, deixando a filiação de ser "um dado da natureza, e sim uma construção cultural, fortificada na convivência, no entrelaçamento dos afetos, pouco importando sua origem". ${ }^{25}$ Portanto, o filho biológico também é adotado pelos pais, pois a filiação se estabelece pelo afeto e não apenas pela hereditariedade, não basta ser pai/mãe biológico, é necessário acolher o filho, desejar ser seu pai ou sua mãe.

Inicialmente, o Estatuto da Criança e do Adolescente (Lei 8.069/1990) regulava apenas a adoção dos meno- res de 18 anos ou daqueles que, apesar de maiores de 18 anos, encontravam-se sob a guarda dos adotantes desde a menoridade. Em perfeita consonância com a Constituição Federal, o estatuto reconheceu os direitos fundamentais da criança e do adolescente, bem como extinguiu o sistema dúplice modelado pelo Código dos Menores de 1979. No entanto, foi apenas no Código Civil de 2002 que a adoção foi unificada, deixando-se, assim, de existir tratamento diferenciado em termos legislativos. ${ }^{26}$

Com o advento da Lei de Adoção/2009, foi delegado de modo expresso ao Estatuto da Criança e do Adolescente o regulamento da adoção dos menores de 18 anos e dos maiores de 18 anos, neste último caso, em relação à aplicação dos princípios norteadores da adoção. Também, foram inseridas algumas novidades no sistema de adoção, como "a adesão do Brasil ao sistema de abertura dos dados, com ampla acessibilidade, por parte do adotado, aos dados relativos a sua origem biológica”. ${ }^{27}$

24 LÔBO, Paulo. Direito Civil: Famílias. p. 272.

25 Idem, p. 273.

26 GAMA, Guilherme Calmon Nogueira da. Direito Civil: Família. p. 422.

27 MONACO, Gustavo Ferraz de Campos. Novo regramento da adoção no direito brasileiro: codificar o mesmo ou um exemplo de codificação a droit constant? In: CHINELLATO, Silmara Juny de Abreu; FUJITA, Jorge Shiguemitsu; SIMÃO, José Fernando; ZUCCHI, Maria Cristina. Direito de Família no Novo Milênio. p. 558. 
Por fim, com relação aos requisitos para a adoção, interessa ao nosso estudo apenas o requisito relativo ao estado civil do adotante. Este tem sua matéria regulada no artigo 42, caput, $\S 2^{\circ}$, $\S 4^{\circ}$ e $\S 6^{\circ}$, do ECA, no qual se verifica que "podem adotar os solteiros, independentemente de sexo, os casados, os divorciados, desde que o estágio de convivência com a criança tenha se iniciado durante o casamento e que estejam de acordo quanto à guarda e às visitas”, ${ }^{28}$ os que vivem em união estável, comprovada a estabilidade familiar e sendo requerida por ambos a adoção, e até os viúvos.

\section{ASPECTOS DA ADOÇÃO HOMOPARENTAL NO BRASIL}

Não há na legislação brasileira norma que equipare de forma expressa a união homoafetiva à união heterossexual, com exceção da Lei Maria da Penha, na qual as uniões homoafetivas foram arroladas dentre as modalidades de entidade familiar. Tendo em vista o descaso legislativo, coube à doutrina e à jurisprudência assegurar aos casais homoafetivos a possibilidade de viver plenamente os seus relacionamentos afetivos e a constituição de família.

Antes do julgamento da Ação Direta de Inconstitucionalidade n. 4277 pelo Supremo Tribunal Federal, considerando a união homoafetiva uma união estável e concedendo aos casais homoafetivos a possibilidade de conversão de sua união em casamento - ou seja, direitos iguais aos desfrutados pelos casais heterossexuais -, a questão da adoção homoparental esbarrava no requisito estado civil do adotante. Isto porque, não sendo as uniões homoafetivas reconhecidas como união estável e, também, não sendo possível sua conversão para casamento, aos casais homoafetivos era possível apenas a adoção por pessoa singular. Logo, constava apenas o nome de um dos parceiros no registro civil de nascimento do adotado, não sendo possível constar o nome de dois pais ou de duas mães. O companheiro cujo nome não constava no registro do filho, ainda assim exercia de forma conjunta a função parental e através da convivência estabelecia um vínculo de afinidade e afetividade, surgido deste a filiação socioafetiva.

A adoção pode ser feita por pessoas solteiras, separadas, divorciadas ou viúvas (hipóteses em que se estará

28 VENOSA, Sílvio de Salvo. Homoafetividade e o direito. In: CHINELLATO, Silmara Juny de Abreu; FUJITA, Jorge Shiguemitsu; SIMÃO, José Fernando; ZUCCHI, Maria Cristina. Direito de Família no Novo Milênio. p. 390. 
diante de uma adoção por pessoas singulares), casadas ou que vivam em união estável (hipóteses em que se estará diante de uma adoção por casais ou adoção conjunta). Ou seja, tanto pode haver uma adoção por pessoas singulares como por duas pessoas. No entanto, nesta última hipótese, a lei exige que as pessoas que desejem adotar uma criança sejam casadas ou conviventes, abrindo apenas aos separados judicialmente ou aos divorciados recentes, na medida em que admite a concessão da adoção aos casais recém desfeitos sempre que o estágio de convivência tenha se iniciado na vigência da sociedade conjugal (art. 42, § 4 , ECA). A nova lei garantiu, sabiamente, tal direito também aos unidos estavelmente que tenham dissolvido a sua união no decorrer do processo de adoção, quando iniciado o estágio de convivência. Em todas essas hipóteses excepcionais a lei só requer o acordo entre os pretensos adotantes no que concerne ao regime de guarda - preferencialmente pela forma compartilhada (art. $\left.42, \S 5^{\circ}, \mathrm{ECA}\right)$ - e visitas, bem como a eventual concessão de alimentos, o que, todavia, poderá e deverá ser fixado judicialmente a posteriori. ${ }^{29}$

Podem adotar todas as pessoas capazes civilmente, com idade superior a dezoito anos, qualquer que seja o seu estado civil. Até porque qualquer pessoa tem direito à convivência familiar, determinada, por exemplo, através da adoção. Assim, uma pessoa solteira, viúva, divorciada etc., pode adotar, desde que revele adequadas condições para a inserção do adotando em núcleo familiar substituto.

Por igual, não se pode cogitar, sequer remotamente, sobre alguma interferência da orientação sexual do adotante no deferimento da adoção. Não é a sua orientação sexual, efetivamente, que definirá a possibilidade da medida, mas a sua conduta que será levada em conta, para a verificação do interesse do adotando. ${ }^{30}$

Filiação adotiva é "filiação que se estabelece em razão da vontade e da afetividade que são reconhecidos como fatores importantes para o fim de a lei permitir a constituição do vínculo de parentesco". ${ }^{31}$ Formado o vínculo socioafetivo entre o adotado e o companheiro do adotante (ou, até mesmo em alguns casos, entre o filho biológico de pai/mãe homossexual e o parceiro homoafetivo de seu genitor), ainda assim não era possível a adoção unilateral, tampouco era possível a

29 MONACO, Gustavo Ferraz de Campos. Novo regramento da adoção no direito brasileiro: codificar o mesmo ou um exemplo de codificação a droit constant? In: CHINELLATO, Silmara Juny de Abreu; FUJITA, Jorge Shiguemitsu; SIMÃO, José Fernando; ZUCCHI, Maria Cristina. Direito de Família no Novo Milênio. p. 559-560.

30 FARIAS, Cristiano Chaves de; ROSENVALD, Nelson. Direito das Famílias. p. 920. 31 GAMA, Guilherme Calmon Nogueira da. Direito Civil: Família. p. 413. 
adoção por casal ou adoção conjunta, pois, conforme já exposto, não era possível constar no registro o nome de dois pais ou de duas mães.

A discussão sobre a possibilidade ou não do registro com o nome de dois pais ou de duas mães, foi tratada pelo judiciário com base nos princípios da dignidade humana, da solidariedade, da não discriminação e da liberdade, bem como levando em conta o melhor interesse da criança e do adolescente. Assim, no ano de 2006 "por decisão unânime, o TJ/RS reconheceu o direito à adoção a um casal formado por pessoas do mesmo sexo. Os filhos haviam sido adotados por uma das parceiras, vindo a outra a pleitear a adoção em juízo”. ${ }^{32}$ Outras decisões favoráveis à adoção homoparental:

FILIAÇÃO HOMOPARENTAL. DIREITO DE VISITAS. Incontroverso que as partes viveram em união homoafetiva por mais de 12 anos. Embora conste no registro de nascimento do infante apenas o nome da mãe biológica, a filiação foi planejada por ambas, tendo a agravada acompanhado o filho desde o nascimento, desempenhando ela todas as funções de maternagem. Ninguém mais questiona que a afetividade é uma realidade digna de tutela, não podendo o Poder Judiciário afastar-se da realidade dos fatos. Sendo notório o estado de filiação existente entre a recorrida e o infante, imperioso que seja assegurado o direito de visitação, que é mais um direito do filho do que da própria mãe. Assim, é de ser mantida a decisão liminar que fixou as visitas. Agravo desprovido. (SEGREDO DE JUSTIÇA) (Agravo de Instrumento n. 70018249631, Sétima Câmara Cível, Tribunal de Justiça do RS, Relatora: Maria Berenice Dias, Julgado em: 11/04/2007).

APELAÇÃO CÍVEL. PEDIDO DE HABILITAÇÃO À ADOÇÃO CONJUNTA POR PESSOAS DO MESMO SEXO. ADOÇÃO HOMOPARENTAL. POSSIBILIDADE DE PEDIDO DE HABILITAÇÃO. Embora a controvérsia na jurisprudência, havendo possibilidade de reconhecimento da união formada por duas pessoas do mesmo sexo como entidade familiar, consoante precedentes desta Corte, igualmente é de se admitir a adoção homoparental, inexistindo vedação legal expressa à hipótese. A adoção é um mecanismo de proteção aos direitos dos infantes, devendo prevalecer sobre o preconceito e a discriminação, sentimentos combatidos pela Constituição Federal, possibilitando, desse modo, que mais crianças encontrem uma famí-

32 DIAS, Maria Berenice; LARRATÉA, Roberta Vieira. A constitucionalização das uniões homoafetivas. In: CHINELLATO, Silmara Juny de Abreu; FUJITA, Jorge Shiguemitsu; SIMÃO, José Fernando; ZUCCHI, Maria Cristina. Direito de Família no Novo Milênio. p. 382. 
lia que lhes conceda afeto, abrigo e segurança. Estudo social que revela a existência de relacionamento estável entre as habilitandas, bem como capacidade emocional e financeira, sendo favorável ao deferimento da habilitação para adoção conjunta, nos termos do $\S 2^{\circ}$ do art. 42 do ECA, com a redação dada pela Lei 12.010/2009. DERAM PROVIMENTO À APELAÇÃO. (SEGREDO DE JUSTIÇA) (Apelação Cível n. 70031574833, Sétima Câmara Cível, Tribunal de Justiça do RS, Relator: André Luiz Planella Villarinho, Julgado em: 14/10/2009).

EMBARGOS INFRINGENTES. PEDIDO DE HABILITAÇÃO. ADOÇÃO CONJUNTA POR PESSOAS DO MESMO SEXO. Sendo admitida, pela jurisprudência majoritária desta corte, a união estável entre pessoas do mesmo sexo, possível admitir-se a adoção homoparental, porquanto inexiste vedação legal para a hipótese. Existindo, nos autos, provas de que as habilitandas possuem relacionamento estável, bem como estabilidade emocional e financeira, deve ser deferido o pedido de habilitação para adoção conjunta. EMBARGOS INFRINGENTES DESACOLHIDOS, POR MAIORIA. (SEGREDO DE JUSTIÇA) (Embargos Infringentes n. 70034811810, Quarto Grupo de Câmaras Cíveis, Tribunal de Justiça do RS, Relator: Sérgio Fernando de Vasconcellos Chaves, Julgado em: 13/08/2010).

Superada em 2011, pelo Supremo Tribunal Federal no julgamento da Ação Direta de Inconstitucionalida- de n. 4277, a questão da igualdade de reconhecimento entre a união estável homoafetiva e a união estável heterossexual, também o requisito legal do estado civil do adotante foi superado definitivamente, permitindo-se aos casais homoafetivos utilizar os institutos da adoção por casais ou adoção conjunta.

CIVIL. PROCESSUAL CIVIL. RECURSO ESPECIAL. UNIÃO HOMOAFETIVA. PEDIDO DE ADOÇÃO UNILATERAL. POSSIBILIDADE. ANÁLISE SOBRE A EXISTÊNCIA DE VANTAGENS PARA A ADOTANDA. I. Recurso especial calcado em pedido de adoção unilateral de menor, deduzido pela companheira da mãe biológica da adotanda, no qual se afirma que a criança é fruto de planejamento do casal, que já vivia em união estável, e acordaram na inseminação artificial heteróloga, por doador desconhecido, em C.C.V. II. Debate que tem raiz em pedido de adoção unilateral - que ocorre dentro de uma relação familiar qualquer, em que preexista um vínculo biológico, e o adotante queira se somar ao ascendente biológico nos cuidados com a criança -, mas que se aplica também à adoção conjunta - na qual não existe nenhum vínculo biológico entre os adotantes e o adotado. III. A plena equiparação das uniões estáveis homoafetivas, às uniões estáveis heteroafetivas, afirmada pelo STF (ADI 4277/DF, Rel. Min. Ayres Britto), trouxe como corolário a extensão automática àquelas, das prerrogativas já outorgadas aos companheiros den- 
tro de uma união estável tradicional, o que torna o pedido de adoção por casal homoafetivo legalmente viável. IV. Se determinada situação é possível ao extrato heterossexual da população brasileira, também o é à fração homossexual, assexual ou transexual, e todos os demais grupos representativos de minorias de qualquer natureza que são abraçados, em igualdade de condições, pelos mesmos direitos e se submetem, de igual forma, às restrições ou exigências da mesma lei, que deve, em homenagem ao princípio da igualdade, resguardar-se de quaisquer conteúdos discriminatórios. V. Apesar de evidente a possibilidade jurídica do pedido, o pedido de adoção ainda se submete à norma-princípio fixada no art. 43 do ECA, segundo a qual "a adoção será deferida quando apresentar reais vantagens para o adotando". VI. Estudos feitos no âmbito da Psicologia afirmam que pesquisas "[...] têm demonstrado que os filhos de pais ou mães homossexuais não apresentam comprometimento e problemas em seu desenvolvimento psicossocial quando comparados com filhos de pais e mães heterossexuais. $\mathrm{O}$ ambiente familiar sustentado pelas famílias homo e heterossexuais para o bom desenvolvimento psicossocial das crianças parece ser o mesmo". ${ }^{33}$ VII. O avanço na percepção e no alcance dos direitos da personalidade, em linha inclusiva, que equipara, em status jurídico, grupos minoritários como os de orientação homoafetiva ou aqueles que têm disforia de gênero -, aos heterossexuais, traz como corolário necessário a adequação de todo o ordenamento infraconstitucional para possibilitar, de um lado, o mais amplo sistema de proteção ao menor - aqui traduzido pela ampliação do leque de possibilidades à adoção e, de outro, a extirpação dos últimos resquícios de preconceito jurídico -, tirado da conclusão de que casais homoafetivos gozam dos mesmos direitos e deveres daqueles heteroafetivos. VII. A confluência de elementos técnicos e fáticos, tirados da i) óbvia cidadania integral dos adotantes; ii) da ausência de prejuízo comprovado para os adotados e; iii) da evidente necessidade de se aumentar, e não restringir, a base daqueles que desejam adotar, em virtude da existência de milhares de crianças que longe de quererem discutir a orientação sexual de seus pais anseiam apenas por um lar, reafirmam o posicionamento adotado pelo Tribunal de origem, quanto à possibilidade jurídica e conveniência do deferimento do pleito de adoção unilateral. Recurso especial NÃO PROVIDO. (Recurso Especial n. 1281093 / SP (2011/0201685-2), Terceira Turma, Superior Tribunal de Justiça, Relatora: Nancy Andrighi, Julgado em: 18/12/2012).

33 FARIAS, Mariana de Oliveira; MAIA, Ana Cláudia Bortolozzi. Adoção por homossexuais: a família homoparental sob o olhar da Psicologia jurídica. Curitiba: Juruá, 2009. p. $75-76$. 
Em sede de adoção, nunca deve ser esquecido que esse instituto na atualidade vê o conforto e a afetividade em prol do menor e apenas secundariamente o interesse dos adotantes. O interesse do menor adotando deve ter sempre prioridade. Essa é certamente a principal razão de a adoção somente ser conferida por sentença judicial em nosso sistema. Sob esse prisma não existe no ordenamento qualquer proibição expressa acerca da adoção por duas pessoas homoafetivas. A complexidade se transportar para a oportunidade de conveniência de cada caso concreto. Sob o ponto de vista dos princípios da igualdade e dignidade da pessoa não há que se ver óbice para essa adoção. [...] É fato que uma vez reconhecida a união de homoafetivos como modalidade de união estável, o passo seguinte é a permissão da adoção. ${ }^{34}$

Sendo assim, atualmente, apesar da inexpressividade da lei na defesa dos direitos dos casais homoafetivos, a jurisprudência inovou e promoveu a igualdade entre a entidade familiar heterossexual e a entidade familiar homoafetiva, desta forma facilitando também a adoção homoparental. A decisão histórica do Supremo Tribunal Federal no julgamento na Ação Direta de Inconstitucionalidade $\mathrm{n}$. 4.277 consiste em indiscutível avanço para os direitos humanos no Brasil, pois não há justificativas para que seja negada a referida equiparação. A defesa das minorias pelo Judiciário - quando o Legislativo abstém-se - é imprescindível para o desenvolvimento salutar da nossa sociedade.

\section{CONCLUSÃO}

Em sede conclusiva, reitera-se que a adoção homoparental é possível hoje em dia graças à decisão proferida pelo Supremo Tribunal Federal no julgamento da Ação Direta de Inconstitucionalidade n. 4.277. Nesta se determinou que as relações homoafetivas são fundadas no afeto mútuo, assim como as relações heterossexuais. Logo, amparados nos princípios da dignidade humana e da igualdade, bem como na analogia, resta indiscutível que situações semelhantes devem receber tratamento idêntico.

Outrossim, demonstrou-se o árduo progresso da questão - adoção homoparental - no território nacional, tendo em vista o entrave causado pela própria negação dos relacionamentos homoafetivos como uniões estáveis, com direito à facilitação da sua conversão para casamento e, logicamente, configurando uma entidade familiar. Devido a este comportamento preconceituoso e claramente exclu- 
dente, as relações de afeto entre pessoas do mesmo sexo por muito tempo ficaram restritas ao campo do Direito Obrigacional, tratadas como sociedades de fato. Negando-lhes o caráter familiar da sua união, a formação de prole através da adoção conjunta restava prejudicada.

Portanto, sendo as uniões homoafetivas semelhantes às heterossexuais, pois têm por base a afetividade, absurdo negar-lhes os mesmos direitos. Claro está que tanto a união es-

\section{REFERÊNCIAS}

BRASIL. Superior Tribunal de Justiça. Recurso Especial n. 1281093/ SP (2011/0201685-2). Relatora: Nancy Andrighi. Órgão Julgador: Terceira Turma. Brasília, 18 de dezembro de 2012. DJe 04/02/2013.

BRASIL. Supremo Tribunal de Federal. Ação Direta de Inconstitucionalidade n. 4.277. Relator: Ayres Britto. Órgão Julgador: Tribunal Pleno. Brasília, 5 de maio de 2011. DJe-198, 14/10/2011.

BRASIL. Tribunal de Justiça do Rio Grande do Sul. Agravo de Instrumento n. 70018249631. Relatora: Maria Berenice Dias. Órgão Julgador: Sétima Câmara Cível. Porto Alegre, 11 de abril de 2007. Diário da Justiça do dia 12/11/2010. tável entre pessoas de sexos diferentes, quanto a união entre pessoas do mesmo sexo, enquadram-se no conceito de entidade familiar. Além disso, atende-se ao melhor interesse do menor para adoção, inseri-lo em uma família disposta a amá-lo e cuidá-lo, sendo irrelevante a identidade sexual dos adotantes a fim de estabelecer a sua capacidade de vivenciar a paternidade responsável. É arcaica a sociedade que não confere dignidade para as suas minorias.

BRASIL. Tribunal de Justiça do Rio Grande do Sul. Apelação Cível No 70031574833. Relator: André Luiz Planella Villarinho. Órgão Julgador: Sétima Câmara Cível. Porto Alegre, 14 de outubro de 2009. Diário da Justiça do dia 12/11/2010.

BRASIL. Tribunal de Justiça do Rio Grande do Sul. Embargos Infringentes n. 70034811810. Relator: Sérgio Fernando de Vasconcellos Chaves. Órgão Julgador: Quarto Grupo de Câmaras Cíveis. Porto Alegre, 13 de agosto de 2010. Diário da Justiça do dia 12/11/2010.

DIAS, Maria Berenice. Manual de Direito das Famílias. 8. ed. São Paulo: Revista dos Tribunais, 2011. 
DIAS, Maria Berenice; LARRATÉA, Roberta Vieira. A constitucionalização das uniões homoafetivas. In: CHINELLATO, Silmara Juny de Abreu; FUJITA, Jorge Shiguemitsu; SIMÃO, José Fernando; e ZUCCHI, Maria Cristina. Direito de Família no Novo Milênio. São Paulo: Atlas, 2010.

FARIAS, Cristiano Chaves de; ROSENVALD, Nelson. Direito das Famílias. 2.ed. Rio de Janeiro: Lumen Juris, 2010. p. 451.

FARIAS, Mariana de Oliveira; BORTOLOZZI MAIA, Ana Cláudia. Adoção por homossexuais: a família homoparental sob o olhar da Psicologia jurídica. Curitiba: Juruá, 2009.

GAMA, Guilherme Calmon Nogueira da. Direito Civil: Família. São Paulo: Atlas, 2008.

GIORGIS, José Carlos Teixeira. Direito de Família Contemporâneo. Porto Alegre: Livraria do Advogado, 2010.

LÔBO, Paulo. Direito Civil: Famílias. 4. ed. São Paulo: Saraiva, 2011.

MONACO, Gustavo Ferraz de Campos. Novo regramento da adoção no direito brasileiro: codificar o mesmo ou um exemplo de codificação a droit constant? In:
CHINELLATO, Silmara Juny de Abreu; FUJITA, Jorge Shiguemitsu; SIMÃO, José Fernando; ZUCCHI, Maria Cristina. Direito de Família no Novo Milênio. São Paulo: Atlas, 2010.

PENA JR., Moacir César. Direito das pessoas e das famílias doutrina e jurisprudência. São Paulo: Saraiva, 2008. p. 170-171.

SIMÃO, José Fernando. Questões Polêmicas: qual o Conceito Jurídico de Família? In: LAGRASTA NETO, Caetano; TARTUCE, Flávio; SIMÃO, José Fernando. Direito de Família. São Paulo: Atlas, 2011.

TARTUCE, Flávio. União Homoafetiva. Comentários ao Julgamento da Apelação Cível nº 643.1794/0, do Tribunal de Justiça de São Paulo, em 17 de Junho de 2009. In: LAGRASTA NETO, Caetano; TARTUCE, Flávio; SIMÃO, José Fernando. Direito de Família. São Paulo: Atlas, 2011.

VENOSA, Sílvio de Salvo. Homoafetividade e o direito. In: CHINELLATO, Silmara Juny de Abreu; FUJITA, Jorge Shiguemitsu; SIMÃO, José Fernando; ZUCCHI, Maria Cristina. Direito de Família no Novo Milênio. São Paulo: Atlas, 2010. 